\title{
DO BIRDS OFA FEATHER COMMUNICATE BETTER? THE COGNITIVE STYLE CONGRUENCE BETWEEN MANAGERS AND THEIR EMPLOYEES AND COMMUNICATION SATISFACTION
}

\author{
Galip E. ERDIL, Cem TANOVA \\ Eastern Mediterranean University \\ Famagusta, North Cyprus \\ via Mersin 10, Turkey \\ E-mail: cem.tanova@emu.edu.tr
}

\begin{abstract}
The paper investigates whether cognitive style congruence of managers and employees on the analytic-intuitive dimension influence employee communication satisfaction. The cognitive style and employee communication satisfaction was measured in 136 manager/employee dyads. Polynomial regression and surface analysis were used to analyze communication satisfaction under four conditions. First, an analytic congruence condition where both manager and employee are analytical, second, an intuitive congruence condition where both are intuitive, third, an incongruence condition where an intuitive manager manages an analytic employee, and fourth, another incongruence condition where an analytic manager manages an intuitive employee. Results supported the similarity effect hypothesis indicating that congruence increases employee communication satisfaction in general. Furthermore, the surface analysis also allowed us to see that the communication satisfaction is higher in the intuitive congruence condition. The study did not support the hypothesis that in incongruent dyads intuitive managers are preferred.
\end{abstract}

Key words: cognitive style, communication satisfaction, banking, North Cyprus

\section{Introduction}

Communication satisfaction has been a popular area of study among business and communication scholars because employee satisfaction with communication has been found to be positively related to many work outcomes such as, job satisfaction, motivation, job performance, organizational commitment, decreased role ambiguity and identification (Blau, Cook, \& Tatum, 2005; Goris, 2007; Gupta \& Sharma, 2008; Kropf, 1999; Lee \& Jablin, 1995). Employees' level of satisfaction with communication is also an important ingredient of the psychological con- tract, and closely linked to whether employees feel valued by their managers and the organization as a whole (Ridder, 2004; Willemyns, Gallois, \& Callan, 2003). Furthermore, employees identify their immediate supervisor as one of the most important of all informational sources (Bartoo \& Sias, 2004) and a supervisor's willingness to share information determines the success of change efforts in organizations (Lewis, 2006). The employee perceptions about how much they are listened to and how much their managers respect their opinions determine their communication satisfaction which in turn influences their feelings of trust towards the organization (Zeffane, 2012).

DOI: $10.21909 /$ sp.2015.03.692 
Personal characteristics influence a manager's attitude towards communication and the employee's expectations in terms of communication modes and frequency. Managers and employees not only differ in terms of their cultural and educational backgrounds and life styles but they also differ in terms of their personality types and cognitive styles. In processing information there are at least two interacting parallel forms (SarmánySchuller \& Kuračka, 2012). The automatic loop evaluates the context implicitly (System 1) and the cognitive loop uses logical reasons to evaluate the situation explicitly (System 2). Although we utilize both systems 1 and 2, style theorists argue that individuals will have a tendency to use one system over the other (Hodgkinson, LanganFox, \& Sadler-Smith, 2008). Cognitive style is defined as the way that individuals prefer to organize information as well as their experiences (Messick, 1976). Cognitive style is often measured on a dimension ranging from intuitive to analytic, which can be related to the automatic (System 1) and cognitive (System 2) loops (Sarmány-Schuller \& Kuračka, 2012). Specifically, intuitive individuals have a global orientation to information processing and are influenced by the context in which the issue is taking place, prefer dealing with unstructured problems and analytic individuals prefer to process information using a step by step approach, focus on issues independently of their context, like precision and prefer structured problems (Armstrong, Cools, \& Sadler-Smith, 2012).

A significant shortcoming of existing studies on cognitive style congruence is the fact that they have used a difference score approach to measure the absolute distance between cognitive style scores of the dyads or a median split approach to categorize the cognitive styles (Allinson, Armstrong, \& Hayes, 2001; Armstrong, Allinson, \& Hayes, 2002, 2004; Armstrong \& Priola, 2001; Lin, Kao, \& Chang, 2010; Vanderheyden \& De Baets, 2015). The difference score fails to differentiate between the relationship among an analytic manager managing an intuitive employee and an intuitive manager managing an analytic employee, since the difference in the scores would be the same in both cases. The median split categories do not tell us how the congruence at high, medium, low scores may lead to different results. In order to remedy the shortcomings of the previous approaches, this study uses polynomial regression and surface analysis as an analytic tool.

Majority of the studies on cognitive style of individuals in dyadic relationships have been conducted in non-work settings such as among teachers and students (Dunn et al., 1990; Packer \& Bain, 1978; Renninger \& Snyder, 1983; Tanova, 2003a), supervisorresearch student (Armstrong et al., 2004) and most were conducted in western settings. Western settings generally provide a lower context culture for communication (Hall, 1976). The western low-context cultures focus on explicitly coded messages where as high-context cultures, such as the Turkish culture, focus on physical context or information internalized in the person during communication while less emphasis is placed on the coded explicitly transmitted part of the message (Bayraktaroğlu \& Sifianou, 2001; Tanova \& Nadiri, 2010). In high context cultures such as our study setting in North Cyprus, communication involves the relationship between the sender and the receiver. In such cultures, meaning is embedded in the context and the communicators rely less on the actual words and instead have to rely 
on subtle cues. This may make cognitive style similarity more important in high context cultures. In high-context cultures, when the manager and employee have similar cognitive styles, they will share similar patterns of thinking and thus a better understanding of implicit meanings that will aid overall communication. Turkish Cypriot culture may result in stronger relationships between cognitive style congruence among dyads and communication satisfaction, compared to the western low context research settings.

This study investigates how manager and employee cognitive style congruence and incongruence on the analytic-intuitive spectrum may influence the employee communication satisfaction. We not only investigate how similarity or dissimilarity influences communication satisfaction, but more importantly, how similarity at the intuitive end or similarity at the analytic end of the spectrum may have different influence on the employee communication satisfaction. Furthermore, we examine when there is dissimilarity between the manager and employee cognitive styles, whether an analytic manager managing an intuitive employee would have different effect on communication satisfaction compared to a situation when an intuitive manager manages an analytic employee. Table 1 shows a summary of the expected relationships.

\section{Hypotheses Development}

According to the similarity-attraction paradigm, similar cognitive styles would lead to increased liking, and therefore higher quality dyadic relationships (Byrne, 1971; Graen \& Uhl-Bien, 1995; Myers \& Myers, 1980). As cognitive styles influence how precisely people perceive, concentrate and how they behave in working towards the achievement of set targets (Sarmány-Schuller \& Šimúth, 2006), we can expect that managers and employees who look at issues from a similar perspective would be able to communicate more effectively compared to those who are dissimilar.

Similar cognitive styles have been found to be associated with mutual positive attitudes between parties in a relationship (Cooper \& Miller, 1991), satisfaction with the relationship (Cooper \& Miller, 1991; Handley, 1982), and effective interpersonal relations (Handley, 1982). Turban and Jones, (1988) observed that when employees perceive their manager as having similar characteristics to themselves, they are more likely to feel more confidence and trust in the manager, furthermore, they reported to be clearer about their roles.

Although studies in the person-environment fit literature have shown support to the idea that manager and employee congruence in personal characteristics lead to better work outcomes (Kristof-Brown, Zimmerman, \& Johnson, 2005), some other studies indicate the performance of dissimilar dyads may be better due to a complimentary fit. For example, in a study among managers and employees in an assisted living and healthcare organization, incongruence in control dimension (dominant vs. submissive) improved subordinate satisfaction (Glomb \& Welsh, 2005). Another study among accounting students demonstrated that when individuals who pay attention to physical reality and focus on details (analytic) are placed in a dyad with those who pay attention to impressions and patterns (intuitive), they performed better in a complex decision task compared to homogeneous dyads (Cheng, Luckett, \& Schulz, 2003). There are also some conflicting results 
in the literature on what happens when the direction of the incongruence is different. Some studies show that analytic managers are preferred even by intuitive followers (Armstrong et al., 2004) whereas others report that intuitive managers are more liked by analytic followers (Allinson et al., 2001).

Although there are some disagreements between earlier (Cooper \& Miller, 1991; Handley, 1982; Turban \& Jones, 1988) and more recent (Allinson et al., 2001; Armstrong et al., 2004; Glomb \& Welsh, 2005; KristofBrown et al., 2005) studies on whether similarity of cognitive style will lead to better communication satisfaction or whether a manager with a certain cognitive style will be preferred by all employees regardless of employee cognitive style match or mismatch, or whether a complimentary cognitive style where differences will improve the communication satisfaction, in the high context cultural environment that we conducted our study, we expect that similarity will lead to improved communication satisfaction. Therefore, we hypothesize that:

Hypothesis 1: The more congruent the employee and manager cognitive styles are at either intuitive or analytic ends of the spectrum, the better communication satisfaction will be.

Managers and employees can be congruent at either high analytic cognitive style (analytic manager supervising analytic employee) or high intuitive cognitive style (intuitive manager supervising intuitive employee). Intuitive employees seek out quick solutions to problems, are swift in decision making and tackle emergencies rapidly even though there may be limited information rather than preferring to follow a certain sequence of tasks. Previous researchers have also speculated whether preference for intu- ition (as a cognitive style) would lead to less information search (Čavojová \& Hanák, 2014). When an intuitive employee teams up with an intuitive manager, their common understanding of how to react to their work environment and communication may encourage them to develop better communication. So, we expect more communication and higher communication satisfaction between employees and managers who have intuitive cognitive style.

On the other hand, individuals who have analytic cognitive style become more rule and procedure dependent rather than going "out of the box" while handling assigned tasks. When an analytic employee teams up with an analytic manager, their common understanding of how to react to work environment and communication may encourage them to have less communication because both will follow what is already structured in order to accomplish assigned tasks. Such individuals may be more reluctant searching for help, may not freely express their own opinions about certain issues, will not use any initiatives to tackle problems, and most importantly they might become withdrawn.

Thus, although in both intuitive - intuitive and analytic - analytic dyads the communication satisfaction will be better compared to incongruent dyads, we expect that communication satisfaction will be higher when both employee and manager are intuitive but comparatively lower when both employee and manager are analytic.

Hypothesis 2: The communication satisfaction between manager and employee is higher when they are high in intuitive cognitive styles compared to the communication satisfaction when they are high in analytic cognitive styles. 
We argued above that cognitive style congruence when both sides are intuitive may not result in the same outcomes as when both sides are analytic, similarly, we can expect that incongruence when manager is intuitive and employee is analytical may lead to different outcomes than when manager is analytical and employee is intuitive. In other words, it is not just similarity or dissimilarity that influences the relationship, but whether the side with higher status is analytical or intuitive.

Some research shows that in organizations intuitive individuals are more likely to rise to managerial positions (Armstrong et al., 2012; Armstrong \& Priola, 2001). This may be due to the fact that intuitive managers seem to be more readily accepted by both intuitive and analytic colleagues, however, analytic managers may have more difficulty in being accepted, especially by intuitive employees (Armstrong \& Priola, 2001). An analytic manager (e.g., task oriented) will focus more on formal procedures and will not be likely to initiate more social-emotional acts towards his/her intuitive subordinates while communicating. Thus, we believe that satisfaction gained from communication interaction between analytic supervisor and intuitive subordinate to be low. On the other hand, when there is incongruence where manager is intuitive, the intuitive manager will be able to initiate social-emotional acts towards his/her analytic subordinates, and will be respected and liked by their analytic as well as intuitive subordinates. Intuitive managers may balance formal procedure with constructive communication interactions through informal communication practices, thus, satisfaction gained from communication interactions between intuitive manager and analytic subordinate is expected to be higher. A study carried out by Armstrong \& Priola (2001) demonstrated that when intuitive individuals are teamed up with analytical colleagues, they engage in better communication practices using both verbal and non-verbal communication, and thus analytic colleagues are satisfied with communication with intuitive colleagues. On the contrary, when analytic individuals are teamed up with intuitive individuals, analytic colleagues engage in more task oriented behaviors, more formal communication practices, obey procedures and may have over reliance on the explicit knowledge. We expect this to be valid and perhaps amplified in the way employees perceive the communication effectiveness of their managers, the intuitive employees are likely to be less tolerant toward analytic managers whereas analytic employees, although their first preference is an analytic manager, will be more tolerant towards an intuitive manager.

Thus, although the incongruent dyads are expected to have lower communication satisfaction compared to congruent dyads in general as we have argued in Hypothesis 1, we expect that communication satisfaction will be higher when manager is intuitive and employee is analytic but comparatively lower when manager is analytic and employee is intuitive.

Hypothesis 3: The employee communication satisfaction is higher when manager is intuitive and employee is analytic, compared to settings when manager is analytic and employee is intuitive.

\section{Method and Sample}

Data were collected from 136 employees and 39 managers in 39 manager-employee groups who participated in this study. The 
Table 1 Summary of expected relationships

\begin{tabular}{cccccc}
\hline Condition & $\begin{array}{c}\text { Congruence/ } \\
\text { Incongruence }\end{array}$ & Manager Employee & $\begin{array}{c}\text { Expected Communication } \\
\text { Satisfaction }\end{array}$ & Hypothesis \\
\hline 1 & Congruence & Intuitive & Intuitive & Highest & H1 \& H2 \\
2 & Congruence & Analytic & Analytic & High but lower than condition 1 & H1 \& H2 \\
3 & Incongruence & Intuitive & Analytic & Low but higher than condition 4 & H3 \\
4 & Incongruence & Analytic & Intuitive & Lowest & H3 \\
\hline
\end{tabular}

size of the groups, including managers, ranged from 3 to 10 . The sample consists of managers and employees from different banks located in different cities in North Cyprus. Both managers and employees were asked to fill out questionnaires assessing their cognitive styles and collecting demographic information. Employees were asked how satisfied they were with communication with their manager. Among the 39 managers there were 30 females and among the 136 employees there were 101 females. The large percentage of female employees (74\%) and managers (77\%) in the Turkish Cypriot banking sector was in line with previous studies (Karatepe et al., 2006; Tanova, 2003b). Participants' years of tenure in the same organization ranged from one to 28 years for managers and one to 23 years for employees. Managers had experience which ranged from one to 20 years with an average of 12 years and standard deviation of 8 years while employees had experience which ranged from one to 23 years with an average of 6 years and standard deviation of 6 years.

\section{Measures}

\section{Cognitive Style Index (CSI)}

The Cognitive Style Index (CSI) (Allinson $\&$ Hayes, 1996), a self-report questionnaire designed to assess the intuitive-analytic dimensions of individuals, was administrated to all participants in the study. The questionnaire consists of 38 items and has a trueuncertain-false response mode, with a score of 2 for true, 1 for uncertain, and 0 for false, being assigned to each response. The direction of scoring depends on the polarity of the item ( 17 items have been reversed to control for acquiescence response bias). Examples of these items are as follows: "When making decisions, I take my time and thoroughly consider all relevant factors" and "I make decisions and get on with things rather than analyze every last detail" (reverse coded). The sum of the 38 items indicates the type of the respondents' cognitive style. The nearer the total score to the theoretical minimum of 0 (zero), the more intuitive the respondent; and the nearer to the theoretical maximum of 76 , the more analytical the respondent. There are no separate scores for intuitive and analytic; a low CSI score means intuitive and a high CSI score means analytic. So, a highly intuitive individual will score low on CSI and a highly analytic individual will score high on CSI.

We have chosen to use CSI to measure cognitive style since it is a simplified and easy to administer measure especially suited for large organizational studies involving managers and professionals (Kozhevnikov, 
2007; Kutschera, 2002). Some other measures of cognitive style have been criticized as being cumbersome or time consuming to be used in hectic work settings (Tanova, 2003a). In a study reviewing 40 years of research in cognitive style, three most commonly used instruments for the assessment of cognitive styles in business and management research were the Myers-Briggs Type Indicator (24\%), the Kirton Adaption-Innovation Inventory (21\%) and the Cognitive Style Index (14\%) (Armstrong et al., 2012).

Reliability of the CSI is good with test-retest correlations ranging from 0.78 to 0.90 and Cronbach alpha coefficients ranging from 0.86 to 0.92 (Allinson \& Hayes, 1996; Armstrong \& Priola, 2001; Armstrong, 1999), more recently, the unifactorial structure of the CSI has been challenged (Hodgkinson et al., 2008) on the basis of dual-processing theory and empirical evidence. Confirmatory factor analysis of the CSI items in the current study supported the single factor model. The Cronbach alpha in the current study is 0.73 for employees and 0.78 for managers.

Communication Satisfaction Questionnaire (CSQ)

In this study, a 46-item Communication Satisfaction Questionnaire (CSQ) developed by (Downs \& Hazen, 1977) was adopted in order to measure the level of communication satisfaction among subordinates. The questionnaire enables respondents to rate their level of satisfaction with eight distinct dimensions on a 7-point Likert-type scale ranging from 7 = Very Satisfied to 1 = Very Dissatisfied (the higher the score of CSQ, the more satisfied the participant is with communication). Examples of these items are as follows: "extent to which my supervisor offers guid- ance for solving job-related problems" and "extent to which my subordinates are receptive to evaluation, suggestions, and criticisms".

The Communication Satisfaction Questionnaire (CSQ) is "arguably the best measure of communication satisfaction in the organizational arena" (Clampitt \& Downs, 1993, p. 6). The reliability of CSQ (Downs \& Hazen, 1977) with test-retest correlation has been found to be .94 (Greenbaum, Clampitt, \& Willihnganz, 1988). The Cronbach alpha in the current study is 0.93 .

\section{Control Variables}

The relationships managers have with their employees in the dyads may also be influenced by the similarity or divergence in terms of the demographic characteristics such as age, gender, education level between managers and employees (Zhang, Wang, \& Shi, 2012). Assuming that this could also influence communication satisfaction, and taking into account that these demographic differences could also influence cognitive styles, we added gender similarity, age dissimilarity (in years), education level dissimilarity (difference between manager and employee education levels where education level was represented as 1, 2 and 3 for high school education, bachelor's degree and masters and above, respectively) and tenure with the same manager as control factors in our regression equation in order to test for the possible effects that they may have.

In order to control for the possibility that the individual's cognitive style score deviates from their group's overall cognitive style score would lead to lower levels of communication satisfaction, we entered the group mean cognitive style level into the regres- 
sion with communication satisfaction as the dependent variable. Perhaps groups with higher CSI (Analytic) or lower CSI (Intuitive) may influence how the members perceive communication satisfaction. Additionally, we have calculated the difference of each individual cognitive style score from their respective group's mean CSI score. This would show how different the individual cognitive style score is from the rest of their group CSI score. We also entered this into the regression to see if this would influence the communication satisfaction.

For control variables measuring dissimilarity we calculated the absolute difference scores and for gender similarity we created a dummy variable (1 indicating "same gender" and 0 indicating "different gender"). In addition, we controlled for the length of time employee manager dyads worked together to partial out the potential familiarity effect (Zhang et al., 2012).

\section{Translation of the Instruments}

The translations of questionnaires from English to Turkish were conducted follow- ing the procedure used in intercultural research. Questionnaires were translated into the local language using a back-to-back translation method (Brislin, 1986). First, the questionnaires were carefully translated from their original English versions into Turkish by the authors of this study. Second, a back translation of the instruments from Turkish to English by a bilingual person was performed. Third, an independent expert reviewed both the original English and the back translated English versions to ensure equivalence of meaning.

\section{Data Analysis and Findings}

Polynomial regression with a surface analysis technique was used in order to evaluate how communication satisfaction would change in congruent and incongruent dyads taking into account congruence and incongruence at intuitive and analytic ends of the dimensions (Edwards, 2002; Jansen \& Kristof-Brown, 2005; Zhang et al., 2012). Studies on cognitive style congruence have mostly used the difference score approach or median split (Allinson et al., 2001;

Table 2 Means, standard deviations, correlations of study variables and reliabilities

\begin{tabular}{llrcccccccc}
\hline Variables & $\mathrm{M}$ & $\mathrm{SD}$ & 1 & 2 & 3 & 4 & 5 & 6 & 7 \\
\hline 1 & Communication Satisfaction & 5.18 & 0.87 & $(0.93)$ & & & & & & \\
2 & Age difference & 10.43 & 5.61 & 0.05 & & & & & & \\
3 & Same Gender & 0.67 & 0.47 & -0.02 & -0.10 & & & & & \\
4 & Education Level Difference & 0.69 & 0.62 & $-0.20^{*}$ & -0.03 & -0.06 & & & & \\
5 & Tenure with the same manager & 3.15 & 2.95 & -0.05 & $-0.29^{* *}-0.10$ & -0.12 & & & \\
6 & Employee Analytic Cognitive Style (E) & 0.88 & 0.62 & -0.03 & 0.00 & 0.11 & 0.02 & -0.04 & $(0.73)$ & \\
7 & Manager Analytic Cognitive Style (M) & 0.88 & 0.53 & 0.12 & -0.06 & $-0.24 * *$ & 0.00 & $0.22^{* *}$ & 0.06 & $(0.78)$ \\
\hline
\end{tabular}

Note. $\mathrm{n}=136$, Cronbach alpha coefficients are reported along the diagonal, Cognitive Style scores have been centered for the analysis

$* \mathrm{p}<0.05, * * \mathrm{p}<0.01$

Two tailed tests. 
Armstrong et al., 2002, 2004; Armstrong \& Priola, 2001; Lin et al., 2010; Vanderheyden \& De Baets, 2015), the polynomial regression analysis approach used in the current study preserves the independent effect of each component measure (Shanock et al., 2010). Polynomial regression and surface analysis allowed us to analyze communication satisfaction in four major settings which would not be possible by using difference scores. Polynomial regressions can be used to generate three-dimensional response surface plots such as the one in Figure 1.

Table 2 shows the means and standard deviations of the study variables and the correlations among these variables. It is in- teresting to note that on average the cognitive style scores were higher compared to studies conducted in Western Europe and North America (see Allinson et al., 2001; Allinson \& Hayes, 1996; Armstrong \& Priola, 2001). Both manager and employee mean scores in the Cognitive Style Index (CSI) were higher than the theoretical mean of 38 . The mean CSI for managers and employees were 49.12 and 49.18. There was no statistically significant difference between the groups $t(192)=-0.072$, ns. The high cognitive style scores are consistent with other studies conducted in societies with high "Uncertainty Avoidance" cultural characteristics (Hofstede \& Hofstede, 2001). In a study

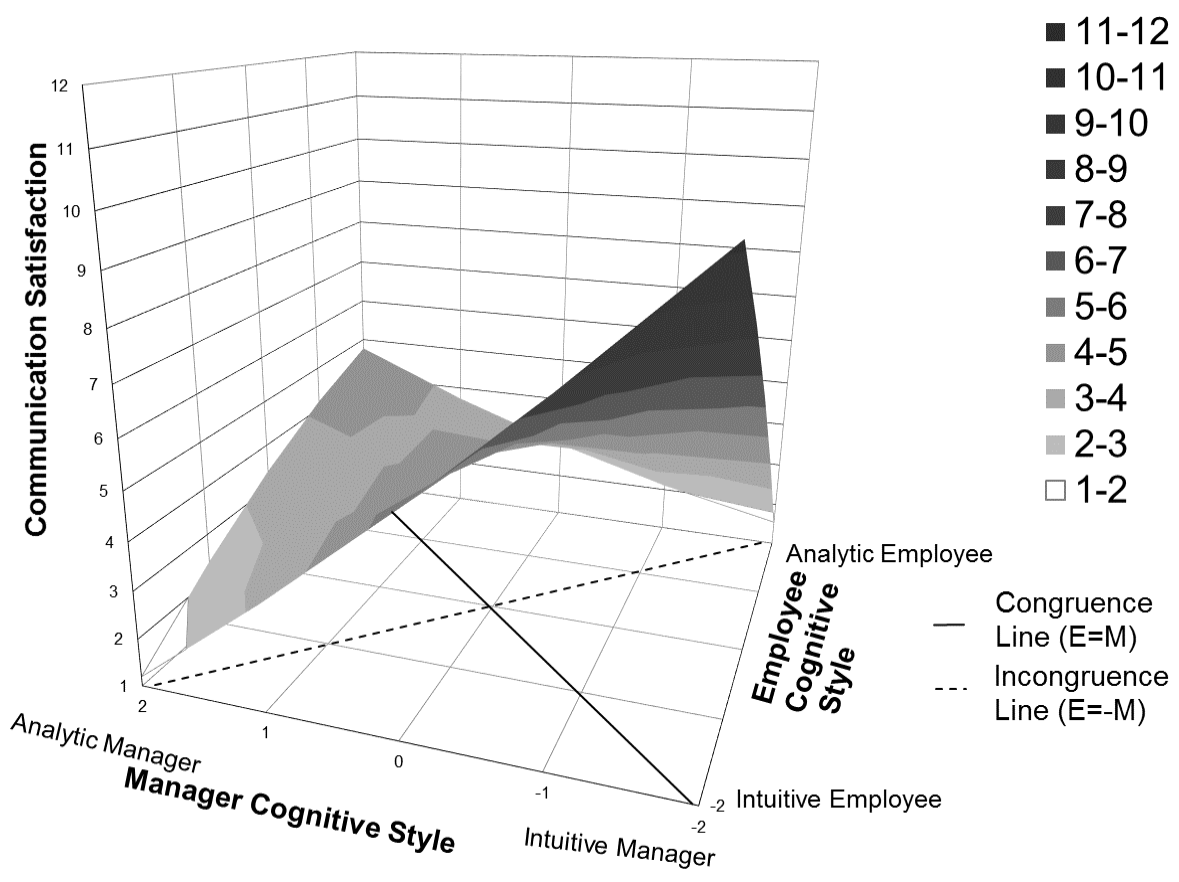

Figure 1 Cognitive style similarity effect and dissimilarity effect on manager and employee communication satisfaction 
of Egyptian, UK and Hong Kong postgraduate and professional development students, UK participants were less analytical compared to those from Egypt and Hong Kong (Savvas, El Kot, \& Sadler-Smith, 2001). In uncertainty avoiding societies there are many formal laws and formal or informal rules to prevent the uncertainties in the behavior of people. There is low tolerance for ambiguity.
The educational and bureaucratic systems in these cultures will reward analytic individuals and attempt to change intuitive types. Therefore, individuals from high uncertainty avoidance cultures will have incentives to be cautious and systematic in their approach to problems (Joy \& Kolb, 2009). Studies report that when an individual's cognitive style differs from the workgroup cog-

Table 3 Polynomial Regressions of Congruent/Incongruent Cognitive Style on Communication Satisfaction controlling for differences in Age, Gender, Education, and Group Cognitive Style

\begin{tabular}{lcl}
\hline Variables & Coefficients & Sig. \\
\hline Constant & 4.518 & $0.002^{* *}$ \\
Age Difference & 0.003 & 0.822 \\
Same Gender & -0.044 & 0.805 \\
Education Level Difference & -0.282 & $0.031^{*}$ \\
Tenure with the same manager & -0.012 & 0.682 \\
Analytic Cognitive Style of the group & 0.032 & 0.284 \\
Individual's difference in Analytic Cognitive & -0.012 & 0.726 \\
Style from their group average & -0.641 & $0.054^{*}$ \\
Employee Analytic Cognitive Style (E) & -0.728 & 0.078 \\
Manager Analytic Cognitive Style (M) & 0.081 & 0.622 \\
$\mathrm{M}^{2}$ & 0.767 & $0.031^{*}$ \\
E×M & -0.101 & 0.65 \\
$\mathrm{E}^{2}$ & & \\
Congruence $(\mathbf{E}=\mathbf{M})$ line & -1.37 & $0.026^{*}$ \\
Slope & 0.75 & $0.027^{*}$ \\
Curvature & & \\
Incongruence $(\mathbf{E}=-\mathbf{M})$ line & 0.09 & 0.841 \\
Slope & -0.79 & 0.169 \\
Curvature &
\end{tabular}

Note. $\mathrm{n}=136$. Unstandardized regression coefficients are reported.

$* \mathrm{p}<.05, * * \mathrm{p}<.01$

Two tailed tests. 
nitive climate there are more communication problems and other performance difficulties (Armstrong et al., 2012). We have investigated if the individual's cognitive style score deviation from their group's overall cognitive style score would lead to lower levels of communication satisfaction. However, we found no relationship between the level of deviation from group score and reported communication satisfaction $(\beta=-0.012, \mathrm{~ns})$.

In testing our hypotheses, we included four control variables that might be related to our dependent variable. In the current study, examination of the demographic control variables and tenure with same manager indicates that only education level difference was significantly related to communication satisfaction $(\beta=-0.28, p<.005)$. Dyads with similar levels of education, reported higher communication satisfaction. Correlation between age difference, gender similarity and tenure with same manager and the dependent variable was not significant .

In Hypothesis 1, we predicted that congruence between employee and manager would positively influence employee communication satisfaction. To test this hypothesis, we regressed the dependent variable on control variables as well as the five polynomial terms, which are, employee CSI (E), manager CSI (M), manager CSI squared (M2), employee CSI times manager CSI (ExM) and employee CSI squared (E2), using polynomial regressions. To reduce multicollinearity and facilitate interpretation of results, CSI values were scale-centered around the mean (Edwards, 2002; Jansen \& Kristof-Brown, 2005; Shanock et al., 2010; Zhang et al., 2012). With communication satisfaction as the dependent variable, we can see from Table 3 the estimated coefficients as well as the slopes and curvatures along congruence and incongruence lines for the polynomial regressions.

To facilitate interpretation of the results, a graph of the response surface analysis is depicted in Figure 1. Figure 1 shows the congruence line represented as a solid line $(\mathrm{E}=\mathrm{M})$ from the front corner (where $\mathrm{E}=\mathrm{M}=-2$ ) to the rear corner (where $\mathrm{E}=\mathrm{M}=2$ ), whereas incongruence line represented as a dashed line from the left corner $(\mathrm{E}=\mathrm{M}=2)$ to the right corner $(E=M=-2)$. The curvature along the congruence line curved downward - i.e., concave $(E=M)$ and the curvature along incongruence line is an inverted U-shape - i.e., convex $(E=-M)$. This indicates that, congruence in both employee and manager with low CSI (intuitive) and employee and manager with high CSI (analytic) conditions improved communication satisfaction. We can see from Table 3 that the curvature is significant (curvature $=0.75, p<.05$ ). The concave graph on the congruence surface line provides evidence for the hypothesized congruence relationship. The curvature that curved downward-i.e., concave along the $\mathrm{E}=\mathrm{M}$ line illustrates that communication satisfaction is higher when an employee's cognitive style is aligned with the manager's, and lateral movement from the congruence line (i.e., shift to its back or front) decreases communication satisfaction, thus supporting Hypothesis 1.

Hypothesis 2 was related to whether congruence in intuitive-intuitive or analytic-analytic results in higher or lower communication satisfaction. The response surface analysis in Figure 1 illustrates that communication satisfaction is greater at the front corner of the congruence line (congruence in intuitive cognitive style, where $\mathrm{E}=\mathrm{M}=-2$ ) than at the rear corner of the congruence line (congruence in analytic cognitive style, where 
$\mathrm{E}=\mathrm{M}=2$ ). Table 3 shows that the slope of the surface along the congruence line is negative and significant $(-1.37, p<.05)$, thus supporting Hypothesis 2.

Although the incongruent dyads are expected to have lower communication satisfaction compared to congruent dyads in general, in Hypothesis 3 we expect that communication satisfaction will be relatively higher when manager is intuitive and employee is analytic (right corner in Figure 1) but relatively lower when manager is analytic and employee is intuitive (left corner in Figure 1). Positive slope along the incongruence $\mathrm{E}=-\mathrm{M}$ line would provide evidence that intuitive managers were liked and accepted by analytic employees in their communication interactions, however, this outcome is not statistically significant (Slope $=.09, p=.84$ ). Therefore, Hypothesis 3 is not supported.

\section{Discussion}

Our results demonstrate the congruence effect on communication satisfaction in a high context cultural study setting. High context cultures have a greater reliance on tacit knowledge instead of explicit knowledge in communication (Möller \& Svahn, 2004). In a study of salespeople and their mentors, Lin, Kao, and Chang (2010) demonstrated that congruence leads to more effective knowledge transfer, especially when the knowledge to be transferred is tacit. When the knowledge to be transferred is explicit, the relationship between congruence and more effective knowledge transfer disappeared. Our results are consistent with this, furthermore, when the congruence was at the intuitive end of the spectrum, the effect was greater on communication satisfaction.
When jobs were much more routine with narrow job descriptions and specialized, analytic cognitive style was seen as a more desired characteristic, especially for employees but also for managers (Dane \& Pratt, 2007). However, using intuition has become a desirable quality in today's rapidly changing business environment that requires more creativity in order to remain competitive (Hodgkinson et al., 2008; Sadler-Smith \& Shefy, 2004). Yet, when intuitive employees do use creativity, the personality incongruence effect identified in the current study may result in the analytic manager interpreting the employee's intuition as a manifestation of the employee not being able to analyze information systematically to reach the optimal solution. Thus, it is critical that managers become aware of their own cognitive styles and how others' styles may differ (Kozhevnikov, 2007). They need to avoid their potential bias towards intuitive or analytic decision making and behaviors.

Our results demonstrated that the incongruence condition when a manager's cognitive style was intuitive and the employee's cognitive style was analytic did not differ in communication satisfaction from the incongruence condition when the manager was analytic and employee was intuitive. Although, today's many authors argue that competitive business environment requires more intuition and creativity from the workforce, the uncertainty avoidant (Hofstede \& Hofstede, 2001) business and educational settings may be rewarding analytic individuals, which may be the reason that contrary to our expectations in Hypothesis 3, analytic employees did not report higher communication satisfaction with intuitive managers. 


\section{Limitations and Suggestions for Further Research}

Several limitations of the current study can provide avenue for future research.

Our study setting, North Cyprus, carries cultural characteristics of Turkish people in their social life and attitudes. According to Hofstede and Hofstede (2001), Turkish culture, to a greater extent, demonstrates collectivist and uncertainty avoidant characteristics, and this may limit the generalizability of the results. In such cultures, employees may place further emphasis on their interactions with their managers towards rapport building. Therefore, a stronger congruence effect may be present in this culture, compared to cultures that are high in individualism, and has high tolerance for ambiguity. Future studies may compare samples from both individualist and collectivist cultures to see if culture makes a difference in how cognitive style congruence and asymmetric incongruence may influence communication satisfaction among dyads.

Second, in the current study number of women participants were higher compared to number of men. Although we have controlled for the role of gender similarity in our analysis, the majority of participants being women in the study raise the likelihood that, since groups studied had more women participants, the majority of manager-employee dyads analyzed were dyads where manager and employee were both women. Earlier research about information processing differences in gender reported that males are largely guided by 'stress assertiveness controlling tendencies, self-efficiency and mastery' in their interactions with others, whereas females are guided by communal concerns 'emphasizing interpersonal affiliation and harmonious relationships' in their interactions with others (Putrevu, 2001). Future research with more male participants may address this limitation to strengthen the congruence effect of communication satisfaction in a dyad, regarding gender differences in cognitive style.

\section{Conclusion and Implications}

Our findings suggest that if managers themselves are not analytic this may prevent analytic employees from reaping the benefits that come with high communication satisfaction. Similarly, when managers are not intuitive, this may cause intuitive employees to have lower communication satisfaction. Therefore, it is critical that the members of a dyad be aware of both parties' cognitive styles in order to improve communication satisfaction and thus build more constructive relationships. This self-awareness will increase the ability to empathize with the other party and thus understand that there may be alternative ways of perceiving, processing and working with information.

Managers should not assume that all employees will share their preferred way of dealing with information (Kozhevnikov, 2007). Since, managers generally do not have the opportunity of selecting employees who are congruent with their own cognitive style and are assigned to manage intact work teams or groups (Zhang et al., 2012), they need to identify differing cognitive style of individuals in their teams and make sure that they are able to accommodate the differences. Moreover, managers need to develop strategies to work with employees that will have different cognitive styles. One strategy can be to determine which tasks to assign to whom 
and the second strategy can be to adjust the way tasks will be performed based on different cognitive styles.

In situations where information at hand requires structured methods of investigation and analytic information processing to reach a favorable outcome, it would be more appropriate to assign such tasks to employees who have analytic cognitive style rather than employees who have intuitive cognitive style. On the other hand, in situations where information at hand requires more innovative and random methods of explorations in processing information, it would be more appropriate to assign such tasks to employees who have intuitive cognitive style rather than employees who have analytic cognitive style.

When analytic managers are communicating with intuitive employees they should first build rapport and allow them greater initiative, autonomy and flexibility rather than restricting them to follow rigid and structured methods. On the other hand, when intuitive managers are leading analytic employees they should develop precise schedules and provide clear structured methods for their analytic subordinates and make use of these employees' strengths in systematic inquiry. Organizations should also provide training and self-development programs in order to facilitate this understanding and to develop synergies.

Received June 6, 2014

\section{References}

Allinson, C., Armstrong, S., \& Hayes, J. (2001). The effects of cognitive style on leader-member exchange: A study of manager-subordinate dyads. Journal of Occupational and Organizational Psychology, 74(2), 201-220. doi:10.1348/ 096317901167316
Allinson, C., \& Hayes, J. (1996). The Cognitive Style Index: A measure of intuition-analysis for organizational research. Journal of Management Studies, 33(1), 119-135. doi:10.1111/j.14676486.1996.tb00801.x

Armstrong, S. (1999). Cognitive style and dyadic interaction: A study of supervisors and subordinates engaged in working relationships. Leeds Univ. (United Kingdom). Retrieved from http:// www.opengrey.eu/item/display/10068/546014

Armstrong, S., Allinson, C., \& Hayes, J. (2002). Formal mentoring systems: An examination of the effects of mentor/protégé cognitive styles on the mentoring process. Journal of Management Studies, 39(8), 1111-1137.

Armstrong, S., Allinson, C., \& Hayes, J. (2004). The effects of cognitive style on research supervision: A study of student-supervisor dyads in management education. Academy of Management Learning \& Education, 3(1), 41-63. doi:10.5465/AMLE.2004.12436818

Armstrong, S., Cools, E., \& Sadler-Smith, E. (2012). Role of cognitive styles in business and management: Reviewing 40 years of research. International Journal of Management Reviews, 14, 238262. doi:10.1111/j.1468-2370.2011.00315.x

Armstrong, S., \& Priola, V. (2001). Individual differences in cognitive style and their effects on task and social orientations of self-managed work teams. Small Group Research, 32(3), 283-312. doi:10.1177/104649640103200302

Bartoo, H., \& Sias, P. M. (2004). When enough is too much: Communication apprehension and employee information experiences. Communication Quarterly, 52(1), 15-26.

Bayraktaroğlu, A., \& Sifianou, M. (2001). Linguistic politeness across boundaries: The case of Greek and Turkish. J. Benjamins Publishing Company.

Blau, G., Cook, K. W., \& Tatum, D. S. (2005). Correlates of peer, supervisor, and patient communication effectiveness satisfaction. Journal of Allied Health, 34(1), 40-46.

Brislin, R. W. (1986). The wording and translation of research instruments. Sage Publications, Inc.

Byrne, D. E. (1971). The attraction paradigm (Vol. 11). New York: Academic Press.

Čavojová, V., \& Hanák, R. (2014). How much information do you need? Interaction of intuitive processing with expertise. Studia Psychologica, 56(2), 83-97.

Cheng, M. M., Luckett, P. F., \& Schulz, A. K. (2003). The effects of cognitive style diversity 
on decision-making dyads: An empirical analysis in the context of a complex task. Behavioral Research in Accounting, 15(1), 39-62. doi: 10.2308/bria.2003.15.1.39

Clampitt, P. G., \& Downs, C. W. (1993). Employee perceptions of the relationship between communication and productivity: A field study. Journal of Business Communication, 30(1), 5-28. doi:10.1177/002194369303000101

Cooper, S. E., \& Miller, J. A. (1991). MBTI learning style-teaching style discongruencies. Educational and Psychological Measurement, 51(3), 699-706.

Dane, E., \& Pratt, M. G. (2007). Exploring intuition and its role in managerial decision making. Exploring Intuition and its Role in Managerial Decision Making, 32(1), 33-54.

Downs, C. W., \& Hazen, M. D. (1977). A factor analytic study of communication satisfaction. Journal of Business Communication, 14(3), 6373.

Dunn, R., Giannitti, M. C., Murray, J. B., Rossi, I., Geisert, G., \& Quinn, P. (1990). Grouping students for instruction: Effects of learning style on achievement and attitudes. The Journal of Social Psychology, 130(4), 485-494.

Edwards, J. R. (2002). Alternatives to difference scores: Polynomial regression and response surface methodology. In F. Drasgow, \& N. W. Schmitt (Eds.), Advances in Measurement and Data Analysis (pp. 350-400). San Francisco: JosseyBass.

Glomb, T. M., \& Welsh, E. T. (2005). Can opposites attract? Personality heterogeneity in supervisor-subordinate dyads as a predictor of subordinate outcomes. Journal of Applied Psychology, 90(4), 749-757.

Goris, J. R. (2007). Effects of satisfaction with communication on the relationship between individual-job congruence and job performance/satisfaction. Journal of Management Development, 26(8), 737-752.

Graen, G. B., \& Uhl-Bien, M. (1995). Relationship-based approach to leadership: Development of leader-member exchange (LMX) theory of leadership over 25 years: Applying a multi-level multi-domain perspective. The Leadership Quarterly, 6(2), 219-247.

Greenbaum, H. H., Clampitt, P., \& Willihnganz, S. (1988). Organizational communication: An examination of four instruments. Management Communication Quarterly, 2(2), 245282 .
Gupta, B., \& Sharma, N. K. (2008). Compliance with bases of power and subordinates' perception of superiors: Moderating effect of quality of interaction. Singapore Management Review, 30(1), $1-24$.

Hall, E. T. (1976). Beyond Culture. Garden City, New York: Anchor.

Handley, P. (1982). Relationship between supervisors' and trainees' cognitive styles and the supervision process. Journal of Counseling Psychology, 29(5), 508-515.

Hodgkinson, G. P., Langan-Fox, J., \& Sadler-Smith, E. (2008). Intuition: A fundamental bridging construct in the behavioural sciences. British Journal of Psychology, 99, 1-27. doi:10.1348/ 000712607 X216666

Hofstede, G. H., \& Hofstede, G. (2001). Culture's consequences: Comparing values, behaviors, institutions and organizations across nations. Sage.

Jansen, K. J., \& Kristof-Brown, A. L. (2005). Marching to the beat of a different drummer: Examining the impact of pacing congruence. Organizational Behavior and Human Decision Processes, 97(2), 93-105. doi:10.1016/ j.obhdp.2005.03.005

Joy, S., \& Kolb, D. A. (2009). Are there cultural differences in learning style? International Journal of Intercultural Relations, 33, 69-85. doi:10.1016/j.ijintrel.2008.11.002

Karatepe, O. M., Yavas, U., Babakus, E., \& Avci, T. (2006). Does gender moderate the effects of role stress in frontline service jobs? Journal of Business Research, 59, 1087-1093. doi:10.1016/ j.jbusres.2006.08.004

Kozhevnikov, M. (2007). Cognitive styles in the context of modern psychology: Toward an integrated framework of cognitive style. Psychological Bulletin, 133(3), 464-481. doi:10.1037/00332909.133.3.464

Kristof-Brown, A. L., Zimmerman, R. D., \& Johnson, C. E. (2005). Consequences of individuals' fit at work: A meta-analysis of personjob, person-organization, person-group, and person-supervisor fit. Personnel Psychology, (58), 281-342.

Kropf, M. B. (1999). Flexibility initiatives: Current approaches and effective strategies. Women in Management Review, 14(5), 177-186.

Kutschera, I. (2002). Cognitive style and decision making: Implications of intuitive and analytical information processing for decision quality. University of Oregon. 
Lee, J., \& Jablin, F. M. (1995). Maintenance communication in superior-subordinate work relationships. Human Communication Research, 22(2), 220-257.

Lewis, L. K. (2006). Employee perspectives on implementation communication as predictors of perceptions of success and resistance. Western Journal of Communication, 70(1), 23-46.

Lin, C. W., Kao, M. C., \& Chang, K. I. (2010). Is more similar, better? Interacting effect of the cognitive-style congruency and tacitness of knowledge on knowledge transfer in the mentorprotégé dyad. Asian Journal of Social Psychology, 13(4), 286-292. doi:10.1111/j.1467839X.2010.01325.x

Messick, S. (1976). Personality consistencies in cognition and creativity. In S. Messick \& Associates (Eds.), Individuality in learning (Vol. 4, p. 22). San Fransisco: Jossey-Bass.

Möller, K., \& Svahn, S. (2004). Crossing East-West boundaries: Knowledge sharing in intercultural business networks. Industrial Marketing Management, 33(3), 219-228.

Myers, I. B., \& Myers, P. B. (1980). Gifts differing: Understanding personality type. Palo Alto. California: Consulting Psychologists Press.

Packer, J., \& Bain, J. D. (1978). Cognitive style and teacher-student compatibility. Journal of Educational Psychology, 70(5), 864-871.

Putrevu, S. (2001). Exploring the origins and information processing differences between men and women: Implications for advertisers. Academy of Marketing Science Review, 10(1), 1-14.

Renninger, K., \& Snyder, S. S. (1983). Effects of cognitive style on perceived satisfaction and performance among students and teachers. Journal of Educational Psychology, 75(5), 668-676.

Ridder, J. A. (2004). Organisational communication and supportive employees. Human Resource Management Journal, 14(3), 20-30

Sadler-Smith, E., \& Shefy, E. (2004). The intuitive executive: Understanding and applying "gut feel" in decision-making. Academy of Management Executive, 18(4), 76-91. doi:10.5465/AME. 2004.15268692

Sarmány-Schuller, I., \& Kuračka, P. (2012). Dimension of the cognitive style "analytical-intuitive" and the successful problem solving in the "IGT" experimental situation. Studia Psychologica, 54(2), 95-110.

Sarmany-Schuller, I., \& Šimúth, J. (2006). Impact of students' cognitive style characteristics on the perception of barriers in online education. Studia Psychologica, 48(3), 265-272.

Savvas, M., El Kot, G., \& Sadler-Smith, E. (2001). Comparative study of cognitive styles in Egypt, Greece, Hong Kong and the UK. International Journal of Training and Development, 5(1), 6473.

Shanock, L. R., Baran, B. E., Gentry, W. A., Pattison, S. C., \& Heggestad, E. D. (2010). Polynomial regression with response surface analysis: A powerful approach for examining moderation and overcoming limitations of difference scores. Journal of Business and Psychology, 25(4), 543-554.

Tanova, C. (2003a). Cognitive styles and learning preferences of undergraduate business students in North Cyprus. Psychological Reports, 93(3f), 1149-1155.

Tanova, C. (2003b). Firm size and recruitment: Staffing practices in small and large organisations in North Cyprus. Career Development International, 8(2), 107-114. doi:10.1108/13620430 310465534

Tanova, C., \& Nadiri, H. (2010). The role of cultural context in direct communication. Baltic Journal of Management, 5(2), 185-196. doi:10.1108/17465261011045115

Turban, D. B., \& Jones, A. P. (1988). Supervisorsubordinate similarity: Types, effects, and mechanisms. Journal of Applied Psychology, 73(2), 228-234.

Vanderheyden, K., \& De Baets, S. (2015). Does cognitive style diversity affect performance in dyadic student teams? Learning and Individual Differences, 38, 143-150. doi:10.1016/j.lindif. 2015.01 .006

Willemyns, M., Gallois, C., \& Callan, V. (2003). Trust me, I'm your boss: Trust and power in supervisor-supervisee communication. International Journal of Human Resource Management, 14(1), 117-127.

Zeffane, R. (2012). Does employee satisfaction with communication affect trust? Longitudinal evidence from an Australian study. International Journal of Business Performance Management, 13(1), 60-74.

Zhang, Z., Wang, M., \& Shi, J. (2012). Leaderfollower congruence in proactive personality and work outcomes: The mediating role of leadermember exchange. Academy of Management Journal, 55(1), 111-130. doi:10.5465/amj. 2009.0865 


\title{
JE KOMUNIKÁCIA ROVNÝ S ROVNÝMLEPŠIA? KONGRUENCIAKOGNITÍVNEHOŠTÝLU MEDZI MANAŽÉRMIA ICH ZAMESTNANCAMI A SPOKOJNOSTI S KOMUNIKÁCIOU
}

\author{
G. E. Erdil, C. T a n ova
}

Súhrn: Článok skúma, či kongruencia kognitívneho štýlu u manažérov a ich zamestnancov $\mathrm{v}$ analyticko-intuitívnej dimenzii ovplyvňuje spokojnost's komunikáciou zamestnancov. Kognitívny štýl a spokojnost's komunikáciou zamestnancov sme sledovali na vzorke 136 dvojíc manažér/ zamestnanec. Použili sme polynomiálnu regresnú a povrchovú analýzu na určenie spokojnosti s komunikáciou v štyroch podmienkach. Prvá podmienka analytickej kongruencie, v ktorej sú manažér aj zamestnanec analytickí, druhá podmienka intuitívnej kongruencie, kde sú obaja intuitívni, tretia podmienka inkongruencie, kde intuitívny manažér riadi analytického zamestnanca a štvrtá, d’alšia podmienka inkongruencie, v ktorej analytický manažér riadi intuitívneho zamestnanca. Výsledky podporili hypotézu efektu podobnosti, podla ktorej kongruencia $\mathrm{v}$ všeobecnosti zvyšuje spokojnost' zamestnanca s komunikáciou. Okrem toho, povrchová analýza nám tiež ukázala, že spokojnost' s komunikáciou je vyššia pri podmienke intuitívnej kongruencie. Štúdia nepodporila hypotézu, podla ktorej sú v inkongruentných dvojiciach podporovaní intuitívni manažéri. 